\title{
Determination of Load Angle for Salient-pole Synchronous Machine
}

\author{
D. Sumina ${ }^{1}$, A. Šala ${ }^{2}$, R. Malarić ${ }^{3}$ \\ Faculty of electrical engineering and computing, University of Zagreb, Unska 3, 10000, Zagreb, Croatia \\ ${ }^{1}$ damir.sumina@fer.hr, ${ }^{2}$ alan.sala@fer.hr, ${ }^{3}$ roman.malaric@fer.hr
}

This paper presents two methods for load angle determination for salient-pole synchronous generator. The first method uses optical encoder to detect the rotor position. In some cases the end of the rotor shaft is not free to be used and mounting of an encoder is impossible. Therefore, the second method proposes estimation of the load angle based on the measured electrical values that have been already used in excitation control system of the synchronous generator. Estimation method uses corresponding voltage-current vector diagram and parameters of the synchronous generator, transformer and transmission lines. Both methods were experimentally verified on the digital control system and synchronous generator connected to power system. The estimation and measured results were compared. The accuracy of load angle estimation method depends on voltage and current measurement accuracy as well as generator, transformer and transmission line parameter accuracy. The estimation method gives satisfactory accuracy for load angles less than $120^{\circ} \mathrm{el}$. Thus, it can be applied in excitation control system to provide stable work of synchronous generator in under-excitation operating area.

Keywords: Load angle measurement, load angle estimation, synchronous generator

\section{INTRODUCTION}

A SYNCHRONOUS GENERATOR connected to a power system needs to remain synchronized in operating conditions even in the case of extreme situations. The exceeding of allowed loading would cause the activation of the generator protection and disconnection of the synchronous generator from the power system. Automatic voltage regulators of synchronous generators have the excitation current limitations dictated by P-Q diagram (Fig.1). This enables optimal utilization of generator loading and safer work of a generator operating in parallel with the power system [1], [2]. If the generator excitation becomes too weak for a particular active power, the magnetic flux in the rotor will not develop the required torque to maintain the generator in synchronism, and the rotor will start to pole slip. Under-excitation (capacitive) operating mode of a synchronous generator appears in systems with underloaded long power transmission lines, by connecting long power transmission lines to voltage and by asynchronous work of regulating transformer regulators.

The load angle is the angular displacement of the generator's rotor from the no-load position referred to as terminal voltage. Load angle provides information about the generator operating point position in relation to the stability limit. The load angle increases with increasing load and under-excitation. Power system is characterized by significant changes in synchronous generator performance, so that the transition from one to another steady operating condition is often accompanied by significant changes in the dynamic load angle. This results in changes of the load angle, in a relatively short period of time, from the maximum to the minimum value. The load angle value is important information especially in the case when generator operates in under-excitation state, because the load angle then assumes the maximum allowed value in relation to the stability limit of synchronous generator operation. The load angle can be used as a measure of how close the generator is to pole slipping and can be also used to limit the excitation current during its operation in capacitive mode [3]-[6]. The application can be also possible in the implementation of the power system stabilizer, where change of the load angle can be used as a stabilizer input signal [7].

The load angle of a synchronous generator is the essential variable for the transient stability studies of power systems [1]. In recent years, an application of the load angle as an input variable in the excitation control and protection systems of synchronous generators and power systems has been investigated [8], [9], [10]. Therefore, real-time measurement of the load angle is required for these applications.

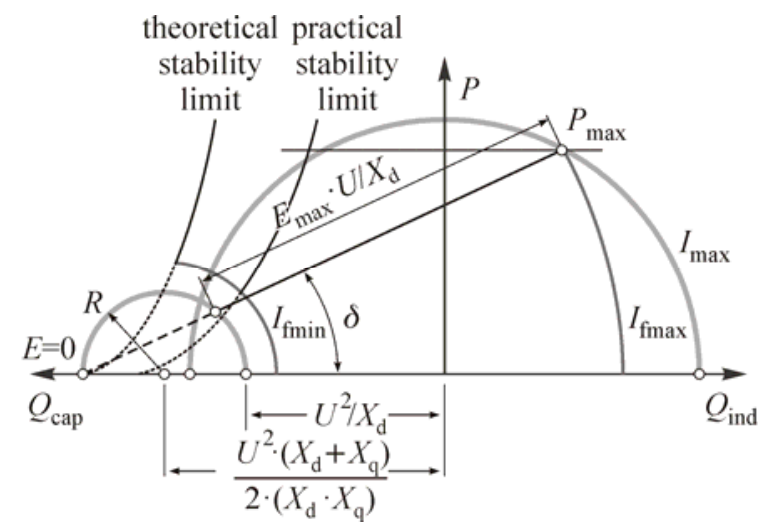

Fig.1. Limitations in the P-Q diagram of the synchronous generator

For the measurement of the load angle, the main problem is the rotor position detection. The load angle measurement system described in [11] uses an optical encoder to detect the rotor position. The load angle was determined by a procedure based on measured terminal voltage and rotor 
position signals. The load angle measurement for detecting the rotor position based on a photoelectric sensor mounted on the stator is proposed in [12]. Air gap sensor for detection of rotor position was proposed in [13]. Disadvantage of these two methods is the mounting of encoder or sensor on the generator. Several other papers have described the procedures for indirect determination of load angle [14]-[17]. Indirect determination is based on available measured values.

This paper presents a load angle measurement using the optical encoder. It also presents the load angle estimation method for synchronous generator connected over the transformer and transmission line to the power system (Fig.2). The proposed estimation method uses the available measured values that have already been introduced for the purpose of the control system excitation. This method has been implemented in the digital control system and requires knowledge of generator and the equivalent network parameters.

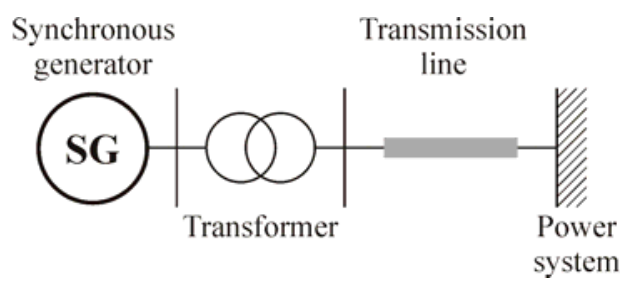

Fig.2. Synchronous generator connected to power system

\section{LOAD ANGLE DETERMINATION}

\section{A. Load angle measurement}

The load angle was measured using optical encoder and the digital control system. The load angle was measured at the exact moment of the network's phase voltage passing through zero, which means that for the power system's frequency of $50 \mathrm{~Hz}$ the sampling frequency is $100 \mathrm{~Hz}$. The angle is measured based on the difference between the momentary position of the rotor and the network phase voltage.

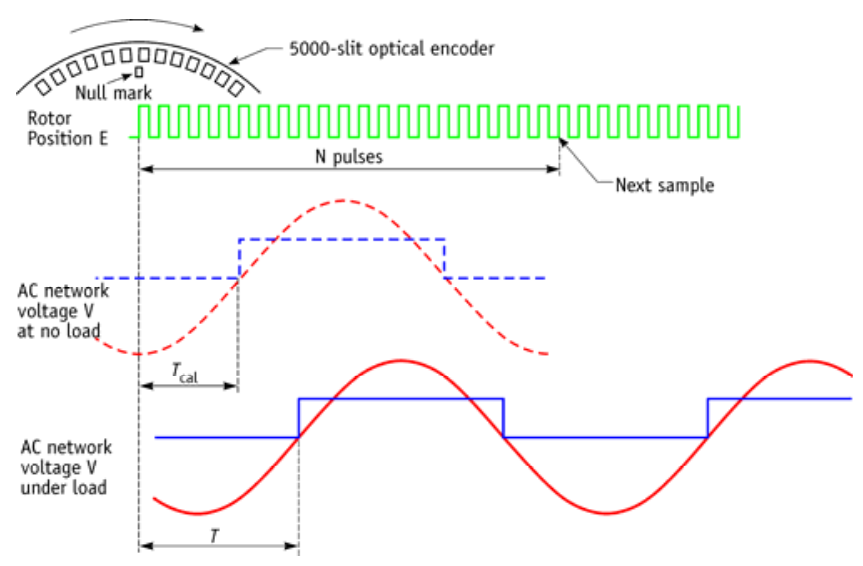

Fig.3. Load angle measurement principle

Fig.3 shows the principle of operation for measuring the load angle. From the optical encoder, two pulse trains are connected to the digital control system. The first pulse train (channel A) has a frequency of 5000 pulses per revolution and the second pulse train (null mark) has a frequency of 1 pulse per revolution.

After the generator is synchronized on the power system with no load and with synchronous speed, calibration procedure is performed. Digital control system detects the time difference between the occurrence of the null mark pulse and the occurrence of the next positive zero crossing of the power system voltage. This time difference is the offset or calibration time, shown as $T_{\text {cal }}$ in Fig.3. As the synchronous generator is loaded, the rotor position pulse advances with respect to the zero crossing of the power system voltage. Thus, the time difference between the occurrence of the null mark pulse and the occurrence of the next positive zero crossing of the power system voltage changes to $T$ in Fig. 3. In this way, the current load angle is given as the time difference:

$$
T_{\delta}=T-T_{\mathrm{cal}}
$$

The load angle is determined by the following expression:

$$
\delta=\frac{T_{\delta}}{T_{v}} \cdot 360^{\circ}
$$

where $T_{\mathrm{v}}$ is the time period of the power system voltage.

If the time is expressed as the number of pulses, then the load angle is determined by:

$$
\delta=\frac{N_{\delta} \cdot \frac{1}{f_{0}}}{N_{v} \cdot \frac{1}{f_{0}}} \cdot 360^{\circ}=\frac{N_{\delta}}{N_{v}} \cdot 360^{\circ}
$$

where $N_{\delta}$ is the number of pulses between the occurrence of the null mark pulse and the occurrence of the next positive zero crossing of the power system voltage, and $N_{\mathrm{v}}$ is the number of pulses in one power system voltage time period. The resolution of load angle measurement is in this case $0.36^{\circ} \mathrm{el}$.

\section{B. Load angle estimation based on the quadrature-axis synchronous reactance and the equivalent reactance of the transformer and transmission line}

For the load angle estimation voltage-current vector diagram is used (Fig.4.), where $\delta_{1}$ is the angle between induced voltage $E_{0}$ and generator voltage $U, \delta$ is the load angle between induced voltage $E_{0}$ and AC network voltage $U_{\mathrm{m}}, I$ is the armature current, $R$ is the equivalent resistance of stator, transformer and transmission line, $X_{\mathrm{e}}$ is the equivalent reactance of the transformer and transmission line and $X_{\mathrm{q}}$ and $X_{\mathrm{d}}$ are synchronous generator reactances.

In [17] the estimation method is proposed based only on the quadrature-axis synchronous reactance $X_{\mathrm{q}}$ and equivalent resistance $R$, whereas the method proposed in this paper includes, in addition, the equivalent reactance of the transformer and transmission line $X_{\mathrm{e}}$.

The load angle is obtained from the diagram in Fig.4: 


$$
\delta=\operatorname{arctg} \frac{I \cdot X_{\mathrm{q}} \cdot P-I \cdot R \cdot Q+X_{\mathrm{e}} \cdot I \cdot P}{U_{\mathrm{m}} \cdot S+I \cdot R \cdot P+X_{\mathrm{q}} \cdot I \cdot Q+X_{\mathrm{e}} \cdot I \cdot Q}
$$

where $\delta$ is the load angle, $I$ is the armature current, $P$ is the active power, $U_{\mathrm{m}}$ is the power system voltage, $Q$ is the reactive power and $S$ is the apparent power. The values of the quadrature-axis synchronous reactance $X_{\mathrm{q}}$, equivalent resistance $R$ and reactance $X_{\mathrm{e}}$ must be known for this estimation method. Measurement of the quadrature-axis synchronous reactance $X_{\mathrm{q}}$ is presented in the next subsection. Reactance $X_{\mathrm{e}}$ is calculated and in p.u. system is equal to 0.1 p.u. and equivalent resistance is equal to 0.01 p.u. In section III it was determined that estimation method in dynamic operations is not significantly dependent on the change of reactance $X_{\mathrm{e}}$.

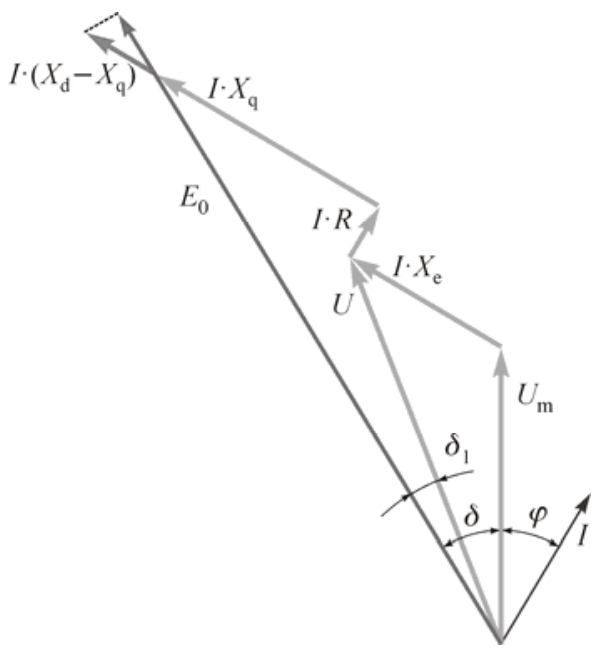

Fig.4 Vector diagram of the synchronous generator connected to AC network

\section{Measurement of the quadrature-axis synchronous reactance}

Usually, the characteristic values of a synchronous machine are obtained from a short-circuit test at no load generator operation. This test implies risks and it cannot be performed every time, so the DC decay test is an alternative method. It determines the characteristic values of a synchronous machine for two axes in function of the saturation state of the leakage paths. In general, the DC decay test is done for positions of the rotor in $d$ - and $q$ - axis [18].

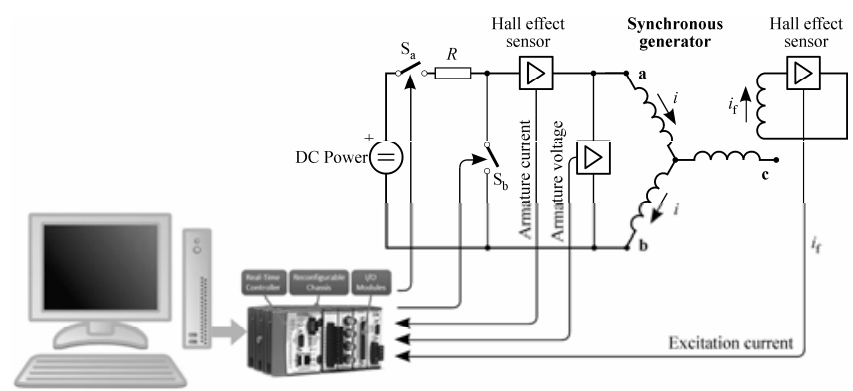

Fig.5. Experimental setup for DC decay test
The standstill DC decay test consists in cutting off the constant DC supply, allowing the current from the coils to reach zero and keeping the rotor in a fix position. The dc flux decay needs a dc source connected to two machine stator phases and the field winding in short-circuit as it is shown in Fig.5.

In order to perform the test, the synchronous generator must be at standstill and positioned either on the $d$ - or $q$ axis. Voltages and currents are measured with Hall-effect sensors.

Initially, the switch $\mathrm{S}_{\mathrm{a}}$ is closed and the stator windings are excited with a constant DC current, which will set up a magnetic flux density along the machine. A small DC excitation current is usually applied; hence, the machine is in the unsaturated condition. Once the stator excitation current is at steady state, the switch $S_{b}$ is closed to shortcircuit the generator stator terminals. The machine voltage and winding currents are acquired at a rate of $5 \mathrm{kHz}$ throughout the transient. The decrement of the stator current during short-circuit is used to determine reactances, time constants and fundamental parameters of the synchronous generator. Derived parameters can be readily obtained. The test duration is considered to be finished when the stator current has reached its steady state on the $d$ - and $q$-axis; in case of testing the direct axis, the field current must also be at steady state. It is important to employ the field current in the estimation process because the model will be able to predict the field winding dynamic behavior with high accuracy. The limiting resistor $R$ will limit the current applied to the machine windings. The value of the resistance must guarantee a negligible current variation before and after the test because the DC source is always connected. The internal resistance of switch $S_{b}$ must have a much lower value than the stator winding resistance; with this consideration, the decrement in the winding currents is not affected. In addition, it is recommended that the current sensor has a low internal resistance when compared to the winding resistance.

The identification procedure starts from a mathematical model, which consists of the machine voltage equations for the $d$ - and $q$-axis. The $d$ - and $q$ - axis current time-variation is considered as being given by a sum of exponential functions, which means, in a per-unit (p.u.):

$$
\begin{gathered}
\frac{i_{d}(t)}{i_{d 0}}=A_{d} \cdot e^{\alpha_{1 d} t}+B_{d} \cdot e^{\alpha_{2 d} t}+C_{d} \cdot e^{\alpha_{3 d} t} \\
\frac{i_{q}(t)}{i_{q 0}}=A_{q} \cdot e^{\beta_{1 q} t}+B_{q} \cdot e^{\beta_{2 q} t}
\end{gathered}
$$

where the coefficients $A, B, C, \alpha$ and $\beta$ are functions of time-constants and reactances for each of the axes [18].

The developed identification program is based on the Gauss-Newton curve fitting algorithm (Fig.6) [19]. Starting from the expressions of the currents, the identification is applied on parts of the curves. Estimated data are used as initial values. 


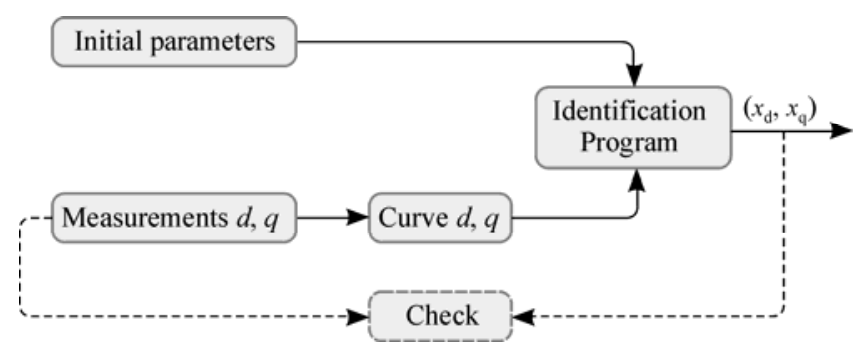

Fig.6. Structure of identification procedure

The identification method gives following results: $X_{\mathrm{d}}=0.8$ p.u and $X_{\mathrm{q}}=0.59$ p.u.

\section{EXPERIMENTAL VERIFICATION OF LOAD ANGLE DETERMINATION METHODS}

Digital control system (Fig.7) based on NI cRIO-9012 [13] was used for excitation control of synchronous generator, as well as to implement the load angle determination methods. The cRIO-9012 controller operates the National Instruments LabVIEW Real-Time Module, while the connectivity to sensors and actuators was obtained with four $\mathrm{I} / \mathrm{O}$ modules, two NI-9215 (16-bit analog input, 100KS/s), NI-9401 (digital I/O, $100 \mathrm{~ns}$ ) and NI-9263 (16-bit analog output, $100 \mathrm{KS} / \mathrm{s}$ ) [20]. NI LabVIEW graphical programming tools can be used for easier modeling of control algorithms. For testing purposes a software monitoring tool was also developed. It enables regulator parameters optimization as well as displaying and recording of the testing results via PC. Experimental setup is presented in Fig.8.

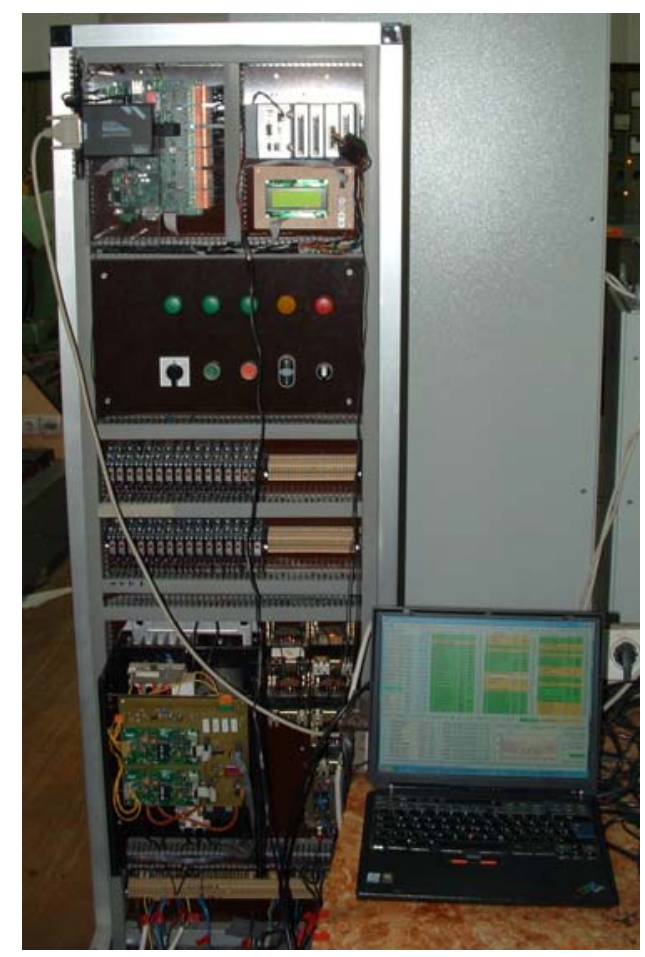

Fig.7. Digital control system

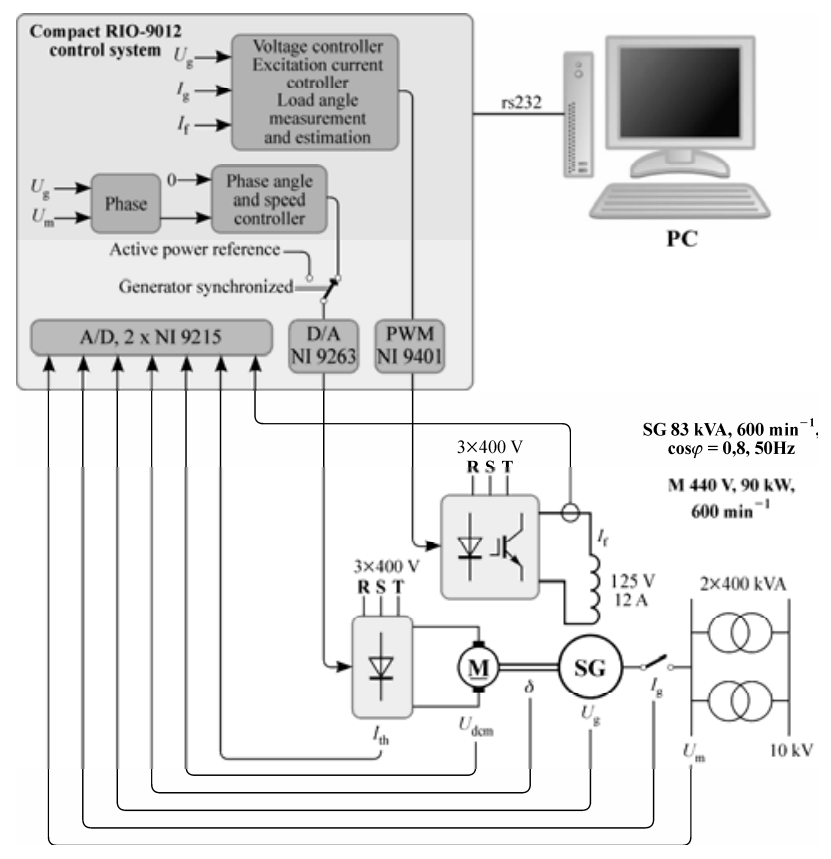

Fig. 8 Experimental setup

\section{A. Static comparison of the measured and estimated load angle}

The static comparison of the measured and estimated load angle was performed by three appropriate experiments. Active power was changed from 0 p.u. to 1.0 p.u. with the step change of 0.2 p.u. In the first experiment (Fig.9), reactive power of the generator is zero.

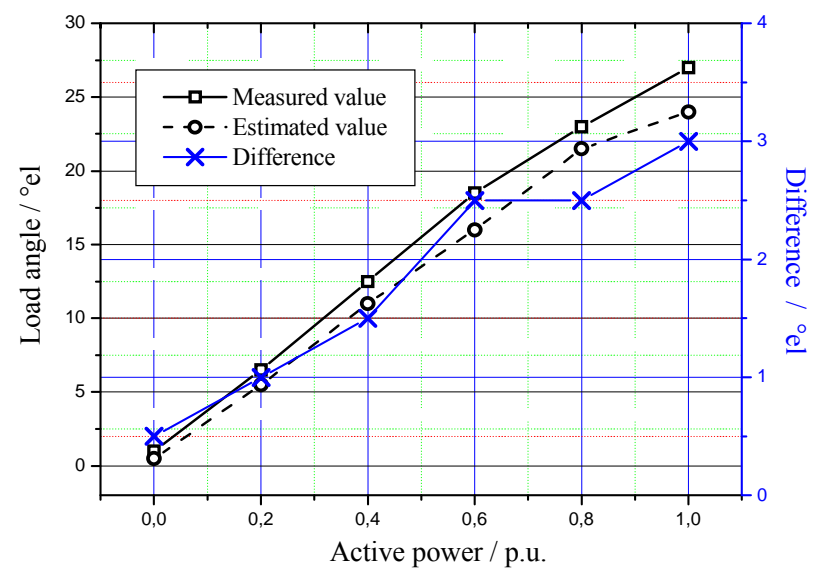

Fig.9. Measured and estimated load angle, and estimation error with reactive power of 0 p.u. during active power change from 0 p.u. to 1.0 p.u.

In the second experiment (Fig.10) the reactive power is inductive (1.0 p.u.) and is kept constant during the whole range of active power change. In the third experiment (Fig.11) reactive power is capacitive and is kept constant (1.0 p.u.). In the whole range of active power change, the difference between estimated and measured load angle is less than $4^{\circ} \mathrm{el}$. 


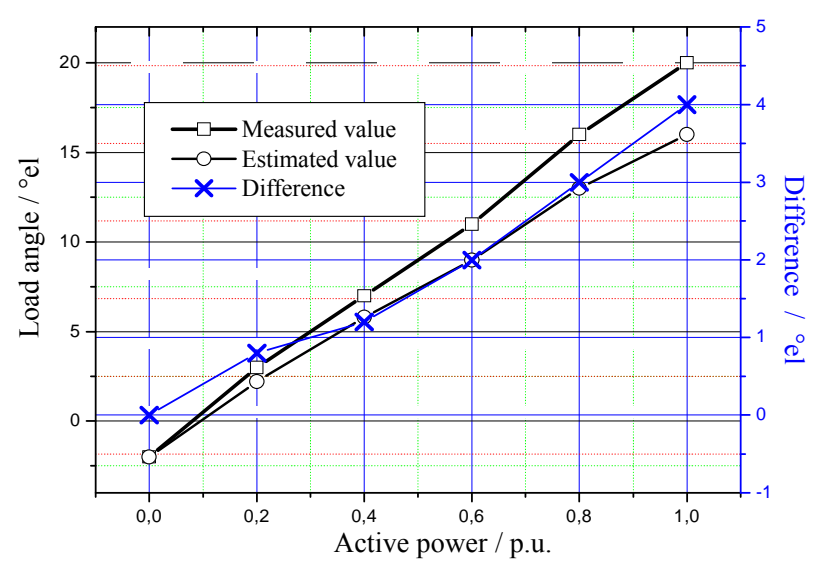

Fig.10. Measured and estimated load angle, and estimation error with inductive reactive power of 1.0 p.u. during active power change from 0 p.u. to 1.0 p.u.

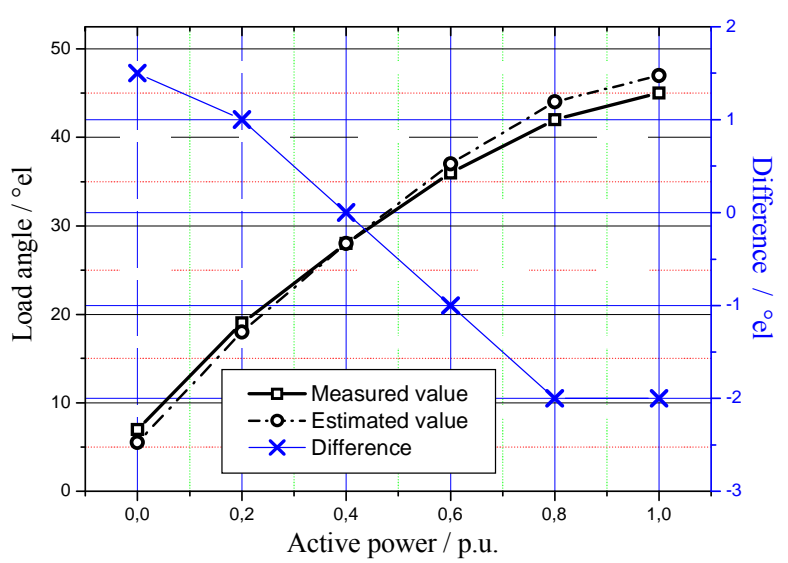

Fig.11. Measured and estimated load angle and estimation error with capacitive reactive power of 1.0 p.u. during active power change from 0 p.u. to 1.0 p.u.

\section{B. Dynamic comparison of the measured and estimated load angle}

The estimated and measured results were also compared with three different experiments. In these experiments there was active power step change (at the moment of $t \approx 1 \mathrm{~s}$ ) from 0 p.u. to 1.0 p.u. and again to 0 p.u. after four seconds. In all experiments the reactive power was kept constant using the reactive power controller. In the first experiment (Fig.12) the reactive power was set to 0 p.u. In the second experiment the generator was in inductive operating mode and reactive power was set to 1.0 p.u. (Fig.13). In the third experiment (Fig.14) the generator was in capacitive operating mode and has lost the synchronism.

Measured and estimated results demonstrate good matching except near the moment when the generator loses synchronism. In that moment the voltage-current vector diagram used as a base in the presented estimation method is not valid. For algorithms that need to keep the generator in stable operating mode, operating range with load angles less than $90^{\circ}$ el. is relevant. So, if excitation control algorithm ensures stable operating mode of a generator, load angle will never exceed $90^{\circ}$ el.

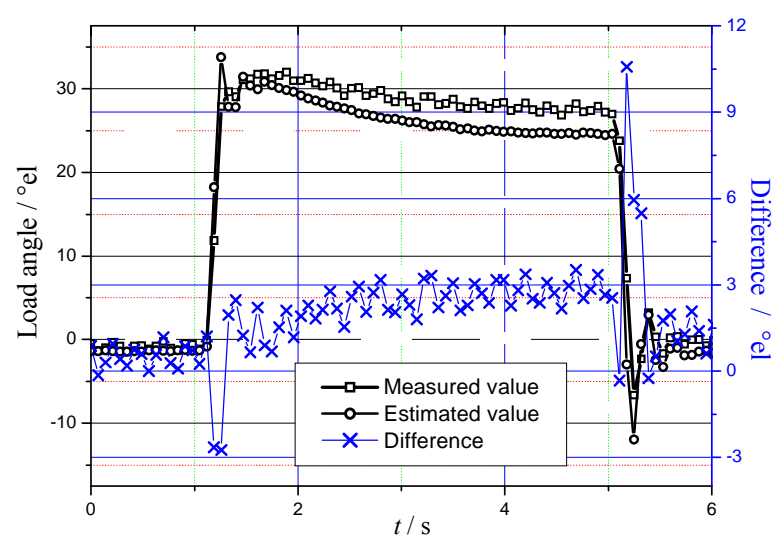

Fig.12. Measured and estimated load angle for active power step change and reactive power of 0 p.u.

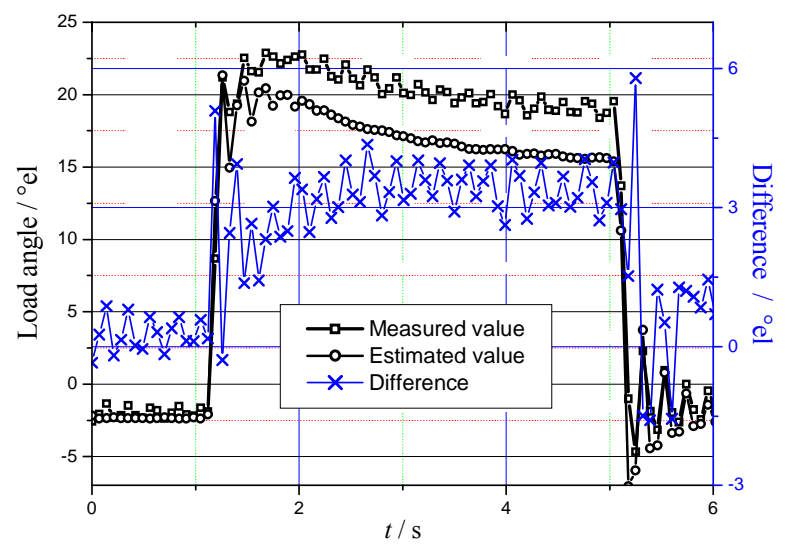

Fig.13. Measured and estimated load angle for active power step change and inductive reactive power of 1.0 p.u.

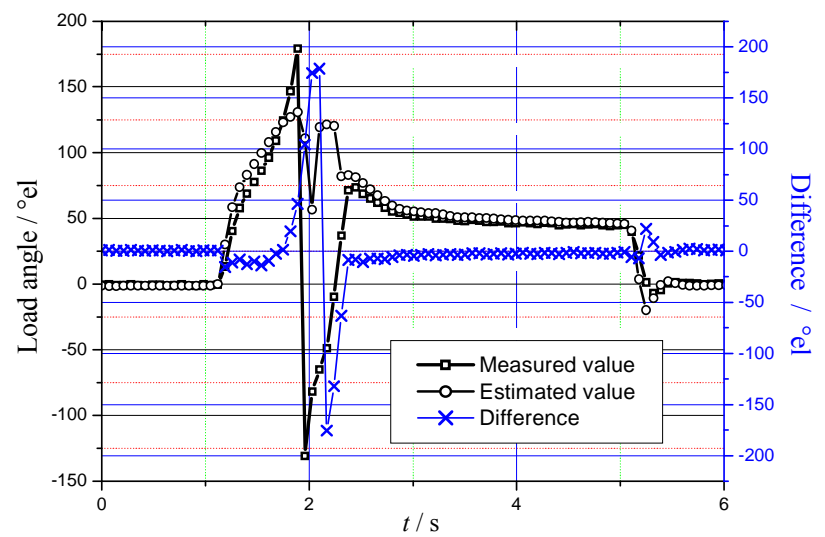

Fig 14. Measured and estimated load angle for active power step change and capacitive reactive power of 1.0 p.u.

\section{Sensitivity of estimation method due to error of estimator parameters}

Parameters needed for the load angle estimation are quadrature-axis synchronous reactance $X_{\mathrm{q}}$, equivalent resistance $R$ and reactance $X_{\mathrm{e}}$. An estimation method dependence of parameters determining accuracy is analyzed in capacitive operating mode with constant reactive power ( 1 p.u.). There is active power step change (at the moment $t=1 \mathrm{~s})$ from 0 p.u. to 1.0 p.u. and again to 0 p.u. after four 
seconds. Stator resistance $R$, quadrature-axis reactance $X_{\mathrm{q}}$ and equivalent reactance $X_{\mathrm{e}}$ in estimator are changed from $50 \%$ to $150 \%$ of nominal value with step of $50 \%$. In the first set of experiments, value of stator resistance in estimator is changed (Fig.15). Two different validation criterions are used to determine sensitivity of estimation method to parameter change. The first criterion is the mean absolute error (MAE) between the measured and estimated load angle. Second criterion is static error (STAT). This error is defined as the absolute error between the measured and estimated load angle 3 seconds after step change of active power. MAE and STAT criterions for stator resistance change are shown in Fig.16. In the second experiment, value of reactance $X_{\mathrm{q}}$ in estimator is changed (Fig.17). MAE and STAT criterions for this set of experiments are shown in Fig.18. In the third experiment, value of reactance $X_{\mathrm{e}}$ in estimator is changed (Fig.19). MAE and STAT criterions for this set of experiments are shown in Fig.20.
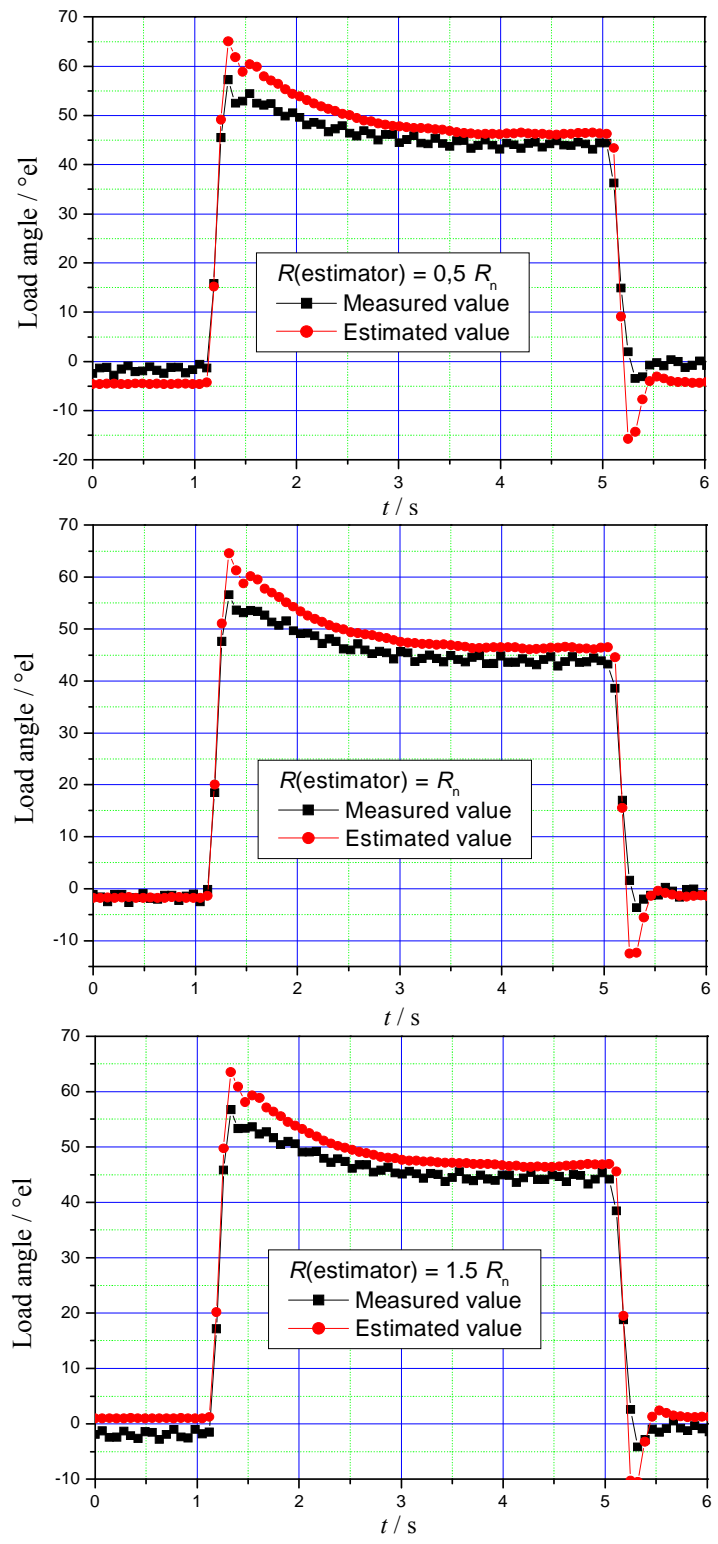

Fig.15. The measured and estimated load angle with different stator resistance $R$ in load angle estimator

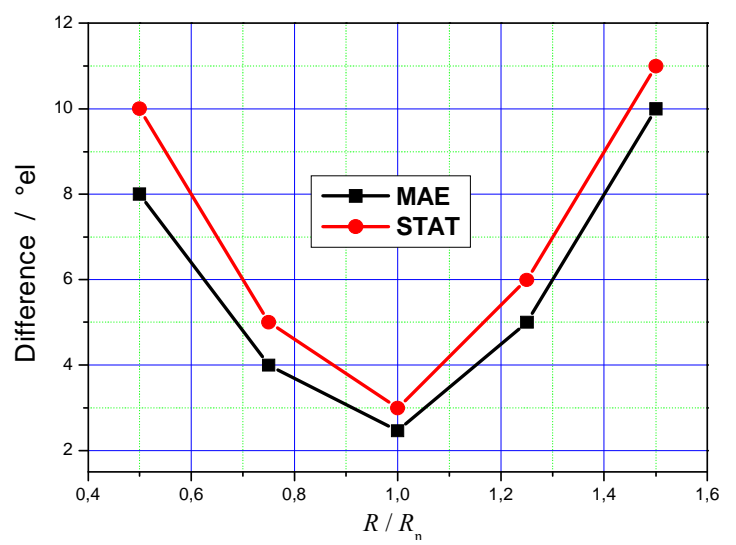

Fig.16. MAE and STAT criterions due to different stator resistance $R$ in estimator
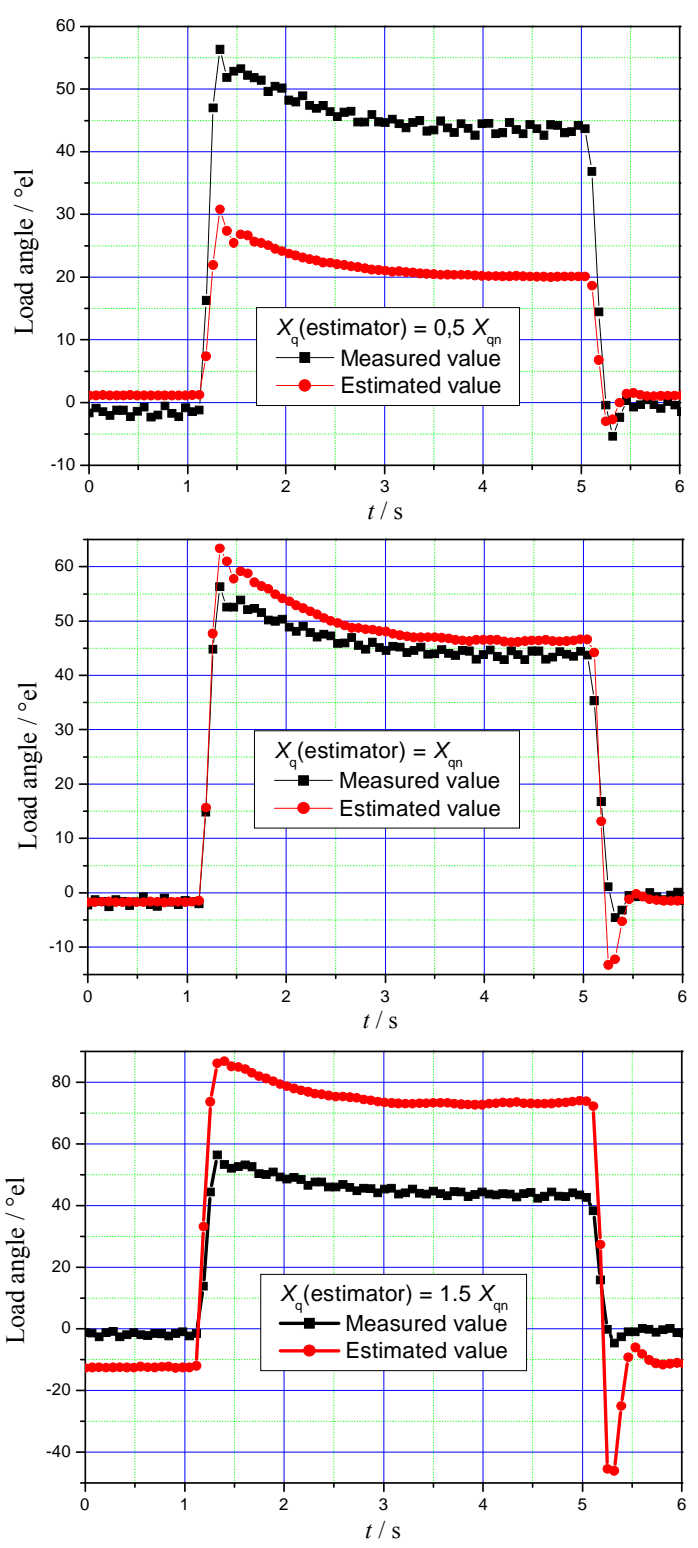

Fig.17. The measured and estimated load angle with different quadrature-axis reactance $X_{\mathrm{q}}$ in load angle estimator 


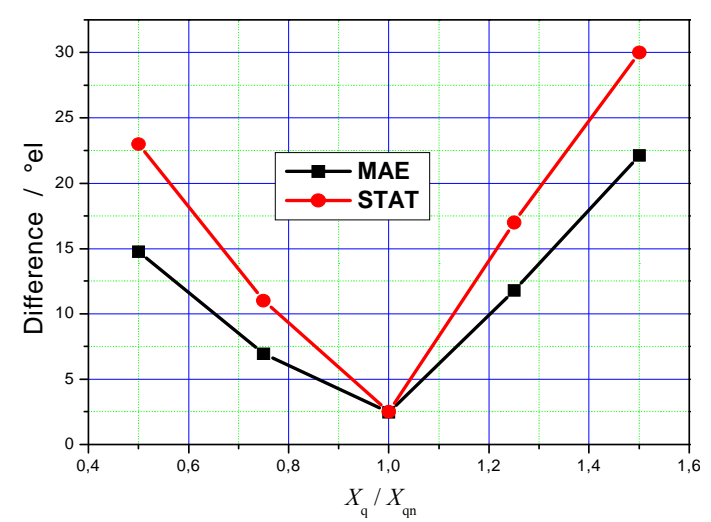

Fig.18. MAE and STAT criterions due to different quadrature-axis reactance $X_{\mathrm{q}}$ in estimator
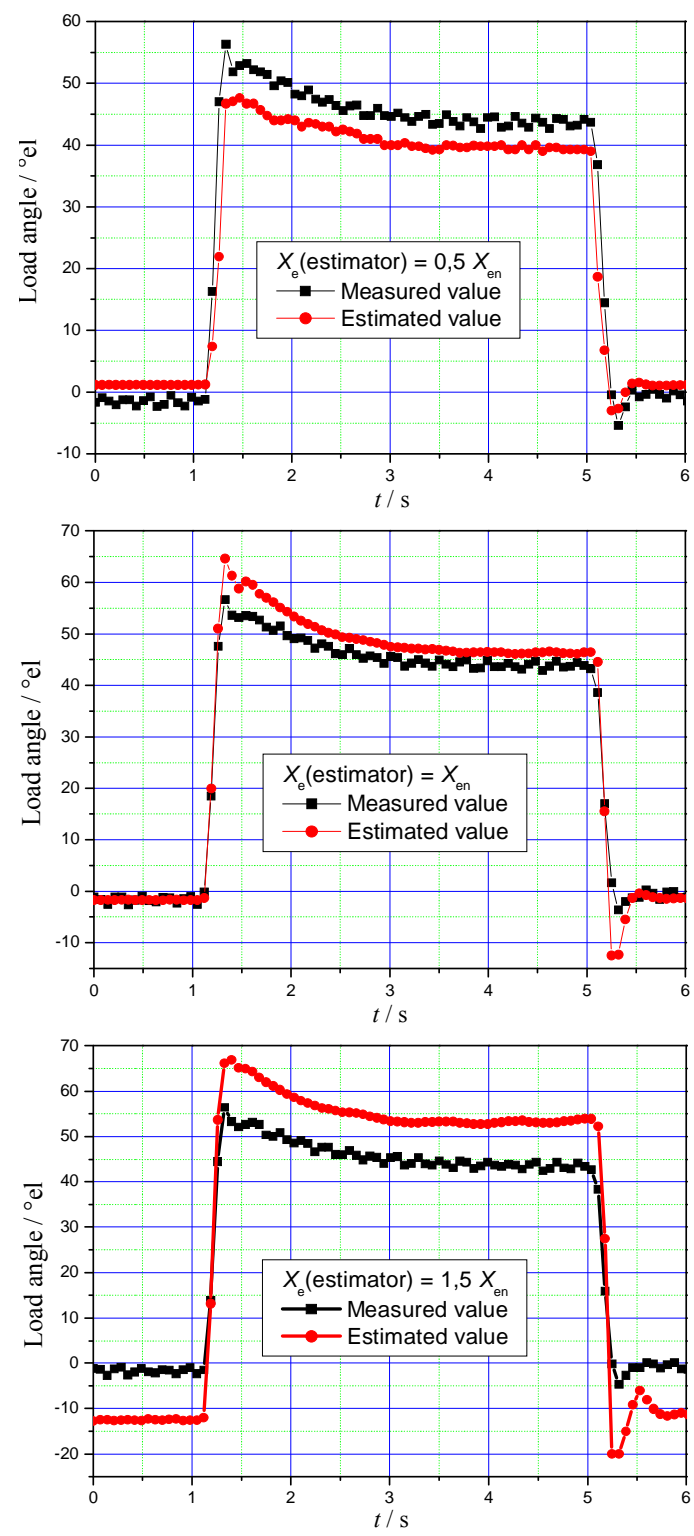

Fig.19. The measured and estimated load angle with different equivalent reactance $X_{\mathrm{e}}$ in load angle estimator

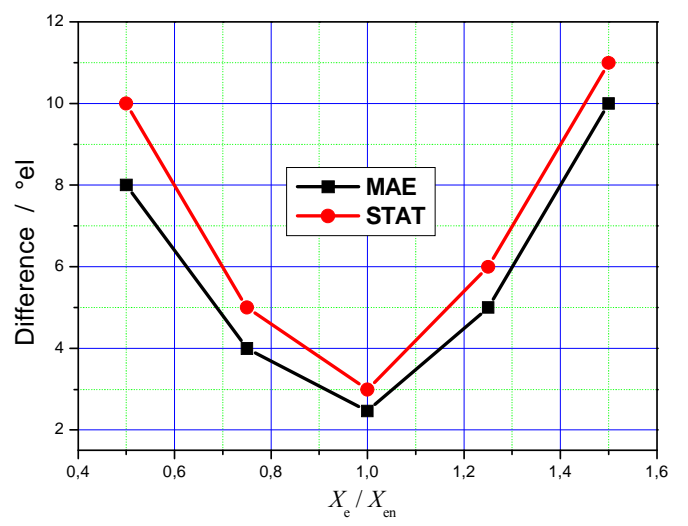

Fig.20. MAE and STAT error of load angle estimation due to different equivalent reactance $X_{\mathrm{e}}$ in estimator

The results of sensitivity analysis show that static accuracy of the presented estimation method is practically independent of errors in determining stator resistance. The average absolute dynamic error is less than $1 \%$ in conditions of stator resistance change. So the determining accuracy of stator resistance value does not have great influence on the accuracy of the presented load angle estimation method.

However, errors in determining the reactances $X_{\mathrm{q}}$ and $X_{\mathrm{e}}$ have influence on the static accuracy of the presented estimation method. The average dynamic absolute error significantly depends on quadrature-axis reactance $X_{\mathrm{q}}$ change.

\section{CONCLUSIONS}

This paper presents and compares methods for the load angle determination for salient-pole synchronous generator. First method presents measurement using an optical encoder to detect rotor position. The load angle is measured against the power system voltage. Second method presents the load angle estimation method based on the measured values (voltages and currents) of synchronous generator. An accuracy of the presented load angle estimation method depends on voltage and current measurement accuracy as well as on parameters determining accuracy (quadratureaxis reactance $X_{\mathrm{q}}$, equivalent resistance $R$ and reactance $X_{\mathrm{e}}$ ). In static conditions the difference between estimated and measured load angle is less than $4^{\circ} \mathrm{el}$. and in dynamic conditions measured and estimated results demonstrate good matching for load angles less than $90^{\circ} \mathrm{el}$.

It was also concluded that errors in generator parameter determination have influence on the static accuracy of the presented estimation method. The average dynamic absolute error significantly depends on generator quadrature-axis reactance change.

Excitation control system with additional signal and estimated load angle can improve the stability of a synchronous generator in capacitive operating mode. Future research will be based on development of excitation control algorithms based on the estimated load angle of a synchronous generator. 


\section{APPENDIX A}

The synchronous generator's rated parameters are:

\begin{tabular}{lr}
\hline Voltage & $400 \mathrm{~V}$ \\
Current & $120 \mathrm{~A}$ \\
Power & $83 \mathrm{kVA}$ \\
Frequency & $50 \mathrm{~Hz}$ \\
Speed & $600 \mathrm{~min}^{-1}$ \\
Power factor & 0.8 \\
Excitation voltage & $100 \mathrm{~V}$ \\
Excitation current & $11.8 \mathrm{~A}$ \\
\hline
\end{tabular}

\section{REFERENCES}

[1] Kundur, P. (1993). Power System Stability and Control. Power System Engineering Series. McGrawHill.

[2] Anderson, P.M., Fouad, A.A. (1994). Power System Control and Stability. IEEE Power System Engineering Series. IEEE Press.

[3] Girgis, G.K., Vu, H.D. (1995). Verification of limiter performance in modern excitation control systems. IEEE Trans. on Energy Conversion, 10 (3), 538-542.

[4] Eberly, T.W., Schaefer, R.C. (1995). Minimum/maximum excitation limiter performance goals for small generation. IEEE Trans. on Energy Conversion, 10 (4), 714-721.

[5] Ramos, A.J.P., Lins, L.R., Fittipaldi, E.H.D., Monteath, L. (1997). Performance of under excitation limiter of synchronous machines for system critical disturbances. IEEE Trans. on Power Systems, 12 (4), 1702-1707.

[6] Working group of the excitation systems subcommittee. (1995). Underexcitation limiter models for power system stability studies. IEEE Trans. on Energy Conversion, 10 (3), 524-531.

[7] Sumina, D., Bulić, N., Erceg, I. (2010). Threedimensional power system stabilizer. Electric Power Systems Research, 80 (7), 886-892.

[8] Chapman, J.W., Ilic, M.D. King, C.A. (1993). Stabilizing a multimachine power system via decentralized feedback linearizing excitation control. IEEE Trans. on Power Systems, 8 (3), 830-839.

[9] Lu, Q., Sun, Y., Xu, Z., Mochizuki, T. (1996). Decentralized nonlinear optimal excitation control. IEEE Trans. on Power Systems, 11 (4), 1957-1962.
[10] Redfern, M.A., Checksfield, M.J. (1995). A new pole slipping protection algorithm for dispersed storage and generation using the equal area criterion. IEEE Trans. on Power Delivery, 10, 194-202.

[11] Barrera-Cardiel, E., Pastor-Gomez, N. (1999). Microcontroller-based power-angle instrument for a power systems laboratory. In Proceedings of the IEEE Power Engineering Society: Summer Meeting. IEEE, 1008-1012.

[12] Chen, Y., Zhang, C., Hu, Z., Wang, X. (2000). A new approach to real time measurement of power angles of generators at different locations for stability control. In Proceedings of the IEEE Power Engineering Society: Winter Meeting. Vol. 2, IEEE, 1237-1242.

[13] Despalatović, M., Jadrić, M., Terzić, B. (2008). Realtime power angle determination of salient-pole synchronous machine based on air gap measurements. Electric Power System Research, 78 (11), 1873-1880.

[14] Cari, E.P.T., Alberto, L.F.C., Bretas, N.G. (2000). A novel methodology for power angle estimation of synchronous generator based on trajectory sensitivity analysis. In Proceedings of the IEEE Power Engineering Society: Winter Meeting. Vol. 2, IEEE, 1237-1242.

[15] Del Angel, A., Geurts, P., Ernst, D., Glavic, M., Wehenkel, L. (2007). Estimation of rotor angles of synchronous machines using artificial neural networks and local PMU-based quantities. Neurocomputing, 70 (16-18), 2668-2678.

[16] Ghahremani, E., Karrari, M., Malik, O.P. (2008). Synchronous generator third-order model parameter estimation using online experimental data. IET Generation, Transmission \& Distribution, 2 (5), 708-719.

[17] Idzotic, T., Erceg, G., Sumina, D. (2004). Load angle estimation of a synchronous generator. In IEEE Mediterranean Electrotechnical Conference. Vol. 3, IEEE, 893-896.

[18] Vicol, L., Tu Xuan, M., Wetter, R., Simond, J.-J., Viorel, I.A. (2006). On the identification of the synchronous machine parameters using standstill DC decay test. In ICEM 2006: International Conference on Electrical Machines.

[19] Malarić, K., Malarić, R., Hegeduš, H. (2008). Gauss Newton curve fitting. http://sourceforge.net/projects/gauss-newton/

[20] National Instruments: CompactRIO. http:/www.ni.com/compactrio/about.htm 